\title{
Frontal extents in virtual environments are not immune to underperception
}

\author{
Jonathan W. Kelly ${ }^{1} \cdot$ William Hammel $^{1} \cdot$ Lori A. Sjolund $^{1} \cdot$ Zachary D. Siegel $^{1}$
}

Published online: 24 June 2015

(C) The Psychonomic Society, Inc. 2015

\begin{abstract}
Distance is commonly underperceived by up to 50 $\%$ in virtual environments (VEs), in contrast to relatively accurate real world judgments. Experiments reported by Geuss, Stefanucci, Creem-Regehr, and Thompson (Journal of Experimental Psychology: Human Perception and Performance, $38,1242-1253,2012)$ indicate that the exocentric distance separating two objects in a VE is underperceived when the objects are oriented in the sagittal plane (depth extents), but veridically perceived when oriented in a frontoparallel plane (frontal extents). The authors conclude that "distance underestimation in the [VE] generalizes to intervals in the depth plane, but not to intervals in the frontal plane." The current experiment evaluated an alternative hypothesis that the accurate judgments of frontal extents reported by Geuss et al. were due to a fortunate balance of underperception caused by the VE and overperception of frontal relative to depth extents. Participants judged frontal and depth extents in the classroom VE used by Geuss et al. and in a sparser VE containing only a grass-covered ground plane. Judgments in the classroom VE replicated findings by Geuss et al., but judgments in the grass VE show underperception of both depth and frontal extents, indicating that frontal extents are not immune to underperception in VEs.
\end{abstract}

Keywords Space perception - Virtual environments . Exocentric distance

Jonathan W. Kelly

jonkelly@iastate.edu

1 Department of Psychology, Iowa State University, W112 Lagomarcino Hall, Ames, IA 50011-3180, USA
Virtual environments (VEs) hold great promise for applications such as training simulations (Grantcharov, Bardram, FunchJensen, \& Rosenberg, 2003), rehabilitation (Jack et al., 2001), and entertainment (Badique et al., 2002). However, one major hindrance to the usefulness of VEs is the tendency for viewers to underperceive depth extents, sometimes by as much as $50 \%$ of the intended depth (e.g., Waller \& Richardson, 2008). Underperception of depth characterizes judgments from oneself to an object (egocentric distance judgments; Loomis \& Knapp, 2003) and also judgments of the distance between two objects separated in depth (exocentric distance judgments in the depth plane; Geuss, Stefanucci, Creem-Regehr, \& Thompson, 2012). Such underperception of depth extents is in sharp contrast to results from real-world studies, where action-based judgments of egocentric distance such as blind walking are often reported to be approximately $100 \%$ of actual distance, ${ }^{1}$ on average, out to $20 \mathrm{~m}$ (Loomis \& Philbeck, 2008).

In contrast to the underperception of depth extents in VEs, a recent study by Geuss et al. (2012) reported surprisingly accurate judgments (approximately $100 \%$ of intended distance) of exocentric extent between objects arranged in a frontal plane (i.e., two objects equidistant from the viewer). Based on this finding the authors conclude that "distance underestimation in the $[\mathrm{VE}]$ generalizes to intervals in the depth plane, but not to intervals in the frontal plane." The goal of the current project was to further evaluate their conclusion.

The basis for the conclusion by Geuss et al. (2012), that distance underperception in VEs characterizes depth extents but not frontal extents, is well demonstrated by their second

\footnotetext{
${ }^{1}$ In contrast to action-based judgments of distance, verbal judgments often indicate underperception (Loomis \& Philbeck, 2008). It is possible that the accuracy of actionbased judgments reflects calibration of motor responses, rather than veridical perception (Durgin, 2014).
} 
experiment. Participants viewed two objects on the ground plane and made judgments of the distance separating the two objects. Objects were arranged either in a depth plane or in a frontal plane. Furthermore, participants viewed the objects in a real environment or in a virtual environment carefully designed to mimic the real environment. After viewing an object pair, participants performed a pantomime walking task (Philbeck, O'Leary, \& Lew, 2004) in which they turned a small amount and then walked a distance that they believed was equivalent to the distance separating the two objects. Judgments of depth extents in the VE were smaller than those in the real world and also smaller than judgments of frontal extents, whereas judgments of frontal extents in the VE did not differ from those in the real world and also did not differ from veridical. These findings were replicated in their third experiment using a different measure of perceived distance.

Although it is possible that distance underperception in VEs only generalizes to depth extents and does not characterize frontal extents, Li, Sun, Strawser, Spiegel, Klein, and Durgin (2013) proposed an alternative interpretation of the Geuss et al. (2012) findings. According to Li et al., accurate judgment of frontal extents in the VE could arise from a fortunate balance of underperception caused by the VE and overperception of frontal relative to depth extents (Kudoh, 2005; Levin \& Haber, 1993; Loomis, Da Silva, Fujita, \& Fukusima, 1992; Loomis, Philbeck, \& Zahorik, 2002). Li et al. (2013) provide evidence for this alternative hypothesis by showing that pantomime walking judgments were larger for frontal compared to depth extents in a real environment and in a virtual environment, but that all extents were perceived as shorter in the virtual compared to real environment, resulting in relatively accurate walking judgments of frontal extents in the VE.

The goal of the current project was to further evaluate $\mathrm{Li}$ et al.'s (2013) hypothesis that the relatively accurate judgment of frontal extents in VEs (Geuss et al., 2012; Li et al.) is due to a balance of overperception of frontal relative to depth extents and overall underperception of distance in VEs. Anecdotal evidence from our laboratory suggests that egocentric distance perception varies considerably across VEs. Studies in the real world indicate that the environmental context influences perceived egocentric distance (Witt, Stefanucci, Riener, \& Proffitt, 2007). The current project compared the relationship between frontal and depth extents in two VEs: the indoor classroom environment used by Geuss et al. (2012) and a barren outdoor environment consisting of a ground plane covered in a grass texture, which has produced relatively large underperception of egocentric distance in our laboratory (Kelly, Hammel, Siegel, \& Sjolund, 2014). Similar outdoor VEs have been used in numerous experiments testing distance perception (Kelly, Donaldson, Sjolund, \& Freiberg, 2013; Li et al., 2013; Messing \& Durgin, 2005; Richardson \& Waller, 2005; Waller \& Richardson, 2008; Wu, He \& Ooi, 2007;
Ziemer, Plumert, Cremer \& Kearney, 2009). We expected that manipulation of the VE (room vs. grass) would affect judgments of depth extents, with smaller judgments in the grass VE compared to the room VE. If frontal extents are accurately perceived in VEs, as proposed by Geuss et al., then judgments of frontal extents should be unaffected by manipulation of the VE. However, if the accurate judgments of frontal extents reported by Geuss et al. were due to a balance of overperception of frontal relative to depth extents and underperception of distance in VEs, as proposed by Li et al., then judgments of frontal and depth extents should be affected by manipulation of the VE.

When viewed under full-cue conditions in the real world, judgments of exocentric extents containing both frontal and depth components have been described as an approximately linear combination of judgments of pure frontal and pure depth extents (Foley, Ribeiro-Filho, \& Da Silva, 2004; Levin \& Haber, 1993; Toye, 1986; Wagner, 1985). In light of the possibility that depth extents in the VEs will be underperceived and frontal extents will be accurately perceived (replicating results of Geuss et al.), we also included stimuli containing both frontal and depth components to evaluate whether the shift from underperception to accurate perception is graded or discrete. The experimental procedure and the virtual reality equipment were very similar to those used by Geuss et al.

\section{Methods}

\section{Participants}

Forty undergraduate students with normal or corrected-tonormal vision participated in exchange for course credit.

\section{Stimuli and design}

Participants judged the exocentric distance separating two virtual objects presented on the ground plane. The virtual environment was either an endless ground plane covered in a grass texture (grass VE; Fig. 1, top) or the room environment (room VE; Fig. 1, bottom) used by Geuss et al. (2012). Objects were 2-D shapes (triangles and pentagons of varying color) separated by exocentric distances of 2,3 , or $4 \mathrm{~m}$. The center of each extent was positioned $5 \mathrm{~m}$ in front of the participant. Stimulus orientation relative to a fronto-parallel plane was $0^{\circ}$ (frontal), $45^{\circ}$, or $90^{\circ}$ (depth). All three independent variables (VE, exocentric distance, and stimulus orientation) were manipulated within participants. Each combination of exocentric distance and stimulus orientation was repeated three times in each VE, resulting in 54 total trials. VE was blocked and order was counterbalanced across participants. Stimuli were presented randomly within each block. 

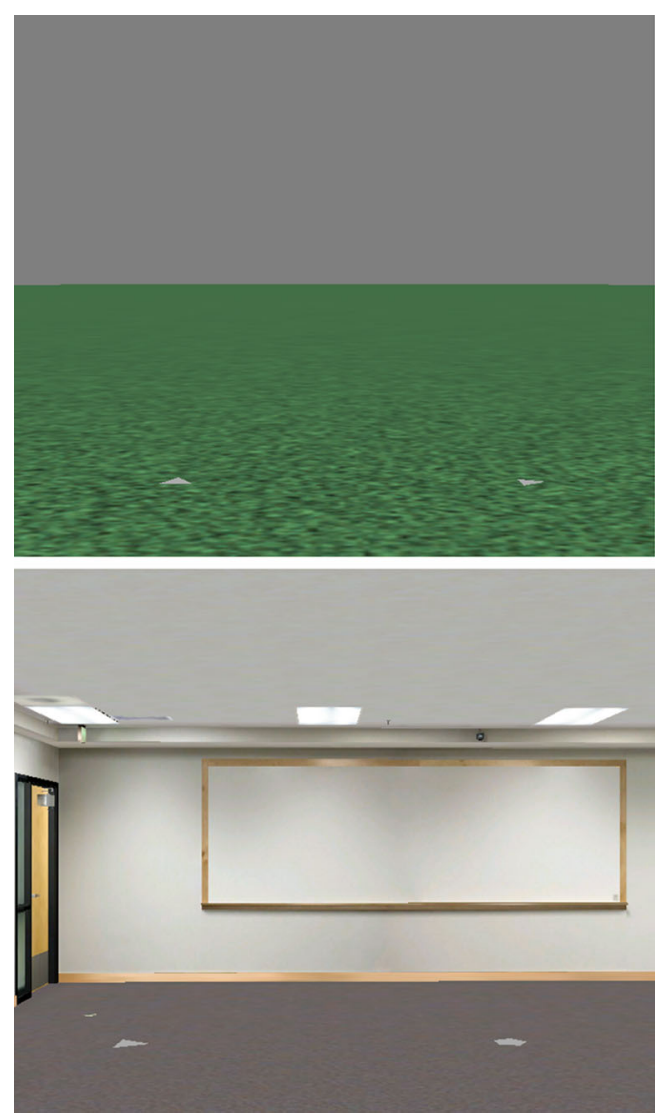

Fig. 1 Perspective views of the grass virtual environment (VE; top) and room VE (bottom)

The VE was presented on a head-mounted display (HMD; nVisor ST50), which provided binocular images at $1280 \times 1024$ resolution that spanned a $40^{\circ}$ horizontal $\times 32^{\circ}$ vertical field of view. Head orientation was tracked using a three-axis orientation sensor (InertiaCube2+ by Intersense), and head position was tracked optically in three dimensions (PPTX4 by WorldViz). Graphics were rendered using Vizard software (WorldViz). Images in the HMD were dynamically updated based on sensed head position and orientation.

\section{Procedure}

Participants were instructed on the pantomime walking task while performing four practice trials in the real lab environment. No feedback was provided during practice or test. After practice, the participant donned the HMD and stood at the viewing location. On each trial, the ground plane and object pair appeared for $10 \mathrm{~s}$ during which the participant was free to make head and trunk movements. After $10 \mathrm{~s}$ the environment was completely occluded (i.e., the display turned black). The participant then turned $30^{\circ}$ to the right and attempted to walk a distance equal to the previously viewed extent. The experimenter then pressed a button that saved the participant's terminal location and the participant was guided without vision back to the viewing location for the next trial.

\section{Results and discussion}

Distance judgments were converted into ratios of walked-toactual distance prior to analysis. The VE variable interacted with environment order, indicating the presence of carryover effects across environments. Therefore, we only interpret data from the first VE (in other words, VE was treated as a between participant variable using data from the first block only; data from the second block were not analyzed further). Judgment ratios (Fig. 2) were analyzed in a mixed-model ANOVA with terms for exocentric distance $(2,3$, or $4 \mathrm{~m})$, stimulus orientation $\left(0^{\circ}, 45^{\circ}\right.$, or $\left.90^{\circ}\right)$, and $\mathrm{VE}$ (room or grass). The main effect of exocentric distance was significant, $F(2,74)=54.95, p<.001$, $\eta_{p}{ }^{2}=.60$, with larger distances producing smaller judgment ratios. The main effect of stimulus orientation was significant, $F(2,74)=54.74, p<.001, \eta_{p}{ }^{2}=.60$, with $0^{\circ}$ stimuli producing larger judgment ratios than $45^{\circ}$ stimuli, and $45^{\circ}$ stimuli producing larger judgment ratios than $90^{\circ}$ stimuli. The main effect of VE was significant, $F(1,37)=17.14, p<.001, \eta_{p}{ }^{2}=.32$, with the room VE producing larger judgment ratios than the grass VE. No interactions were significant.

Depth extents $\left(90^{\circ}\right.$ stimuli) were underperceived relative to frontal extents $\left(0^{\circ}\right.$ stimuli), regardless of the environment. This result replicates numerous real world studies showing that stimulus orientation affects perceived exocentric distance (Kudoh, 2005; Levin \& Haber, 1993; Li et al., 2013; Loomis et al., 1992, 2002; but see the real world conditions of Geuss et al., 2012, and Kelly, Loomis, \& Beall, 2004). Furthermore, judgments of both frontal and depth extents were smaller in the grass VE than the room VE. In the grass VE, underperception was severe enough that both depth and frontal extents were underperceived relative to veridical. But in the room VE, only depth extents were underperceived, and frontal judgments did not differ from veridical.

The results from the room VE replicate those reported by Geuss et al. (2012), who concluded that distance underperception in VEs characterizes depth extents but not frontal extents. However, the addition of the grass VE condition in the current project makes it clear that their conclusion only characterizes responses in the room VE. In the grass VE, both depth and frontal extents were underperceived. As proposed by Li et al. (2013), the room VE caused underperception in near-perfect balance with the overperception of frontal relative to depth extents, leading to veridical judgments of frontal extents. However, such veridical judgments of frontal extents in the room VE should not be considered representative of perceived frontal extents in all VEs. Rather, a more general description of exocentric distance perception in VEs is that both depth and frontal extents are 


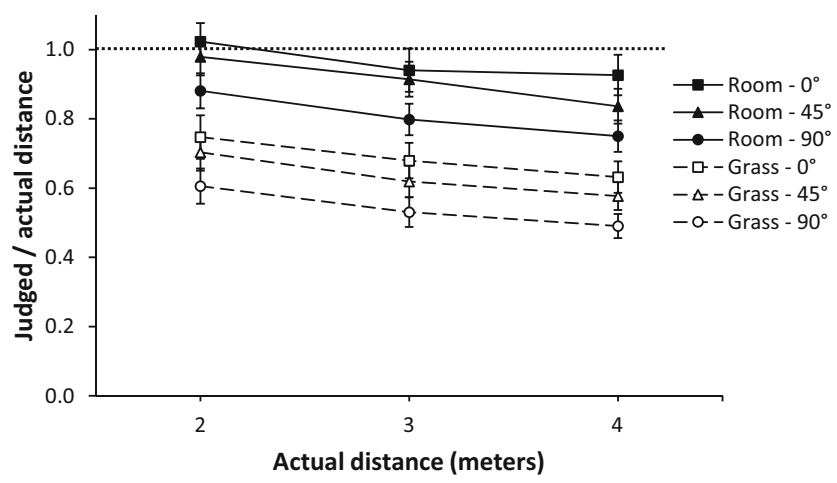

Fig. 2 Average distance judgment ratios as a function of actual exocentric distance, virtual environment, and viewing angle. Error bars represent \pm 1 SEM. The dotted line at 1.0 represents veridical performance

subject to underperception, which is more severe for depth than frontal extents.

Distance judgments were smaller in the grass VE than in the room VE, regardless of stimulus orientation. The current project was not designed to identify the factors leading to underperception of distance in VEs, but much previous work has addressed this topic. It is possible that underperception in virtual, compared to real, environments is due to missing or degraded distance cues. Potential cues that have received research attention include graphics quality (Kunz, Wouters, Smith, Thompson, \& Creem-Regehr, 2009; Thompson et al., 2004), field of view (Knapp \& Loomis, 2004; Willemsen, Colton, Creem-Regehr \& Thompson, 2009), stereoscopic cues (Willemsen, Gooch, Thompson, \& Creem-Regehr, 2008), and the mass and inertia of the HMD (Willemsen et al., 2009). However, none of those cues is singularly responsible for the underperception that characterizes distance perception in VEs. Recent research using newer HMDs has reported nearveridical judgments of egocentric distance (Li, Zhang, \& Kuhl, 2014; Young, Gaylor, Andrus, \& Bodenheimer, 2014), but the reason for the reported differences between HMDs is unknown. Distance judgments in the VE conditions of Li et al. (2013; experiment 2) were larger than those in the current experiment. The VE used by $\mathrm{Li}$ et al. is quite similar to the grass VE in the current experiment, but differences in overall judgment accuracy might be attributable to the wide field of view HMD used by $\mathrm{Li}$ et al. $\left(126^{\circ}\right.$ compared to $40^{\circ}$ horizontal; but see Knapp \& Loomis, 2004). We can therefore only speculate as to why distance judgments in the current experiment were smaller in the grass VE than in the room VE.

It is possible that the effect of VE was due to environmental context. For example, Witt et al. (2007) reported that egocentric distance judgments were approximately $10 \%$ larger when there was little open space beyond the target object, compared to when there was considerable open space beyond the target. Therefore, the effect of the VE manipulation in the current project could have been partially caused by the amount of open space beyond the targets. However, distance judgments were $44 \%$ larger in the room than the grass VE, which exceeds the $\sim 10 \%$ effect reported by Witt et al., indicating that other factors may also be responsible for the difference between VEs.

Both the room VE and the grass VE contained numerous distance cues, including declination angle, texture gradient, binocular disparity, binocular convergence, and motion parallax. However, only the room VE contained familiar size cues (e.g., the doors and whiteboard visible in Fig. 1, bottom) and linear perspective (lines formed by intersections between the walls and floor/ceiling planes), and either cue could have been responsible for the differences between VEs. Experimental manipulation of linear perspective cues affects perceived distance, perhaps by influencing perceived eye level (Wu, Zhou, Shi, He, \& Ooi, 2015). It is therefore possible that the linear perspective cue was responsible for judgment differences across the two VEs. Future work could manipulate the presence of familiar objects and walls within the grass VE and compare distance judgments to those made in the room VE to evaluate the influences of familiar size and linear perspective.

The conclusion that the room VE caused distance underperception that was offset by overperception of frontal extents relative to depth extents contrasts somewhat with the real world data reported by Geuss et al. (2012). In their realworld classroom condition, judgments of frontal and depth extents did not differ from one another. There is no obvious explanation as to why the real classroom would produce equivalent judgments of depth and frontal extents whereas the replica classroom VE would produce underperception of depth extents relative to frontal extents. Using a similar pantomime walking task, Li et al. (2013) reported overperception of frontal relative to depth extents in real and virtual outdoor environments, with overall larger judgments in the real compared to virtual environment, which stands in contrast to the Geuss et al. results using indoor environments. Although the real world data from Geuss et al. may complicate a general description of exocentric distance perception, they do not bear directly on the conclusions from the current study. In particular, the manipulation of VE (grass vs. room) in the current study clearly demonstrates that both frontal and depth extents in virtual environments can be subject to underperception, and that this underperception is more pronounced for depth extents than frontal extents.

The $45^{\circ}$ stimulus orientation was included to determine whether there was a gradual or discrete shift from underperception of depth extents to accurate perception of frontal extents. However, this secondary research question was rendered less interesting in light of the primary finding that frontal extents were not accurately perceived across all virtual environments. Instead, the finding that extent judgments of the $45^{\circ}$ stimuli were in between judgments of the $0^{\circ}$ and $90^{\circ}$ stimuli (in both VEs) corroborates other research 
indicating a linear relationship between stimulus orientation and perceived exocentric extent (Foley et al., 2004; Levin \& Haber, 1993; Toye, 1986; Wagner, 1985). In both the grass VE and the room VE, the relationship between distance judgment ratio and stimulus orientation was well described by a linear function (grass: slope $=-.072, \mathrm{R}^{2}=.98$; room: slope $=-.077$, $\left.\mathrm{R}^{2}=.97\right)$. Similar results were obtained using a finer sampling of stimulus orientation in a separate experiment measuring perceived exocentric extent in the grass VE. ${ }^{2}$

The results of this project are based on pantomime walking to reproduce exocentric extents, and it is unclear whether the results would generalize to other response types. Whereas Geuss et al. (2012) found that the results of their pantomime walking task generalized to a blind throwing task, $\mathrm{Li}$ et al. (2013) report differences between pantomime walking and a visual matching task. Furthermore, Philbeck et al. (2004) report differences between verbal, direct blind walking, and pantomime walking. Some of those differences might be due to recalibration of perceived distance traveled when walking without visual feedback.

In summary, frontal extents were overperceived relative to depth extents, regardless of whether they were viewed in a sparse grass VE or a more articulated room VE. This overperception of frontal relative to depth extents appears to be in near-perfect balance with the underperception caused by the room VE, leading to veridical judgments of frontal extents. However, results from the grass VE make it clear that frontal extents are not immune to underperception of distance in virtual environments, and that exocentric distance perception depends on both the stimulus orientation as well as characteristics of the VE.

Acknowledgments The authors thank Jack Loomis for discussion and comments on an earlier draft, and Michael Geuss, Jeanine Stefanucci, Sarah Creem-Regehr, and Bill Thompson for sharing their 3D model.

\section{References}

Badique, E., Cavazza, M., Klinker, G., Mair, G., Sweeney, T., Thalmann, D., \& Thalmann, N. (2002). Entertainment applications of virtual environments. In K. M. Stanney (Ed.), Handbook of virtual environments: Design, implementation, and applications (pp. 1143-1166). Mahwah, NJ: Erlbaum.

Durgin, F. H. (2014). Angular scale expansion theory and the misperception of egocentric distance in locomotor space. Psychology \& Neuroscience, 7, 253-260.

${ }^{2}$ In this unpublished experiment, stimulus orientation was manipulated to be $0,26.7,45,63.4$, or $90^{\circ}$, and only the grass VE was used. All stimulus orientations were underperceived, replicating the grass VE data reported above. Furthermore, the relationship between distance judgment ratio and stimulus orientation was well described by a linear function (slope $=$ $\left.-.045, \mathrm{R}^{2}=.95\right)$.
Foley, J. M., Ribeiro-Filho, N. P., \& Da Silva, J. A. (2004). Visual perception of extent and the geometry of visual space. Vision Research, 44, 147-156.

Geuss, M. N., Stefanucci, J. K., Creem-Regehr, S. H., \& Thompson, W. B. (2012). Effect of viewing plane on perceived distances in real and virtual environments. Journal of Experimental Psychology: Human Perception and Performance, 38, 1242-1253.

Grantcharov, T. P., Bardram, L., Funch-Jensen, P., \& Rosenberg, J. (2003). Learning curves and impact of previous operative experience on performance on a virtual reality simulator to test laparoscopic surgical skills. The American Journal of Surgery, 185(2), 146-149.

Jack, D., Boian, R., Merians, A., Tremaine, M., Burdea, G., \& Adamovich, S. (2001). Virtual reality-enhanced stroke rehabilitation. IEEE Transactions on Neural Systems and Rehabilitation Engineering, 9, 308-318.

Kelly, J. W., Donaldson, L. S., Sjolund, L. A., \& Freiberg, J. B. (2013). More than just perception-action recalibration: Walking through a virtual environment causes rescaling of perceived space. Attention, Perception, \& Psychophysics, 75, 1473-1485.

Kelly, J. W., Hammel, W., Siegel, Z. D., \& Sjolund, L. A. (2014). Recalibration of perceived distance in virtual reality occurs rapidly and transfers asymmetrically across scale. IEEE Transactions on Visualization \& Computer Graphics, 22, 588-595.

Kelly, J. W., Loomis, J. M., \& Beall, A. C. (2004). Judgments of exocentric direction in large-scale space. Perception, 33, 443-454.

Knapp, J. M., \& Loomis, J. M. (2004). Limited field of view of headmounted displays is not the cause of distance underestimation in virtual environments. Presence: Teleoperators and Virtual Environments, 13, 572-577.

Kudoh, N. (2005). Dissociation between visual perception of allocentric distance and visually directed walking of its extent. Perception, 34, $1399-1416$.

Kunz, B. R., Wouters, L., Smith, D., Thompson, W. B., \& Creem-Regehr, S. H. (2009). Revisiting the effect of quality of graphics on distance judgments in virtual environments: A comparison of verbal reports and blind walking. Attention, Perception, \& Psychophysics, 71, 1284-1293.

Levin, C. A., \& Haber, R. N. (1993). Visual angle as a determinant of perceived interobject distance. Perception and Psychophysics, 54, 250-259.

Li, Z., Sun, E., Strawser, C. J., Spiegel, A., Klein, B., \& Durgin, F. H. (2013). On the anisotropy of perceived ground extents and the interpretation of walked distance as a measure of perception. Journal of Experimental Psychology: Human Perception and Performance, 39, 477-493.

Li, B., Zhang, R., \& Kuhl, S. (2014). Minification affects action-based distance judgments in oculus rift HMDs. Proceedings of the ACM Symposium on Applied Perception, 91-94.

Loomis, J. M., Da Silva, J. A., Fujita, N., \& Fukusima, S. S. (1992). Visual space perception and visually directed action. Journal of Experimental Psychology: Human Perception and Performance, 18, 906-921.

Loomis, J. M., \& Knapp, J. M. (2003). Visual perception of egocentric distance in real and virtual environments. In L. J. Hettinger \& M. W. Haas (Eds.), Virtual and adaptive environments (pp. 21-46). Mahwah NJ: Erlbaum.

Loomis, J. M., \& Philbeck, J. W. (2008). Measuring perception with spatial updating and action. In R. L. Klatzky, M. Behrmann, \& B. MacWhinney (Eds.), Embodiment, ego-space, and action (pp. 143). Mahwah, NJ: Erlbaum.

Loomis, J. M., Philbeck, J. W., \& Zahorik, P. (2002). Dissociation between location and shape in visual space. Journal of Experimental Psychology: Human Perception and Performance, 28, 1202-1212.

Messing, R., \& Durgin, F. H. (2005). Distance perception and the visual horizon in head-mounted displays. ACM Transactions on Applied Perception, 2, 234-250. 
Philbeck, J. W., O’Leary, S., \& Lew, A. L. B. (2004). Large errors, but no depth compression, in walked indications of exocentric extent. Perception \& Psychophysics, 66, 377-391.

Richardson, A. R., \& Waller, D. (2005). The effect of feedback training on distance estimation in virtual environments. Applied Cognitive Psychology, 19, 1089-1108.

Thompson, W. B., Willemsen, P., Gooch, A. A., Creem-Regehr, S. H., Loomis, J. M., \& Beall, A. C. (2004). Does the quality of the computer graphics matter when judging distances in visually immersive environments? Presence: Teleoperators and Virtual Environments, $13,560-571$

Toye, R. C. (1986). The effect of viewing position on the perceived layout of space. Perception \& Psychophysics, 40, 8592.

Wagner, M. (1985). The metric of visual space. Perception \& Psychophysics, 38, 483-495.

Waller, D., \& Richardson, A. R. (2008). Correcting distance estimates by interacting with immersive virtual environments: Effects of task and available sensory information. Journal of Experimental Psychology, Applied, 14, 61-72.

Willemsen, P., Colton, M. B., Creem-Regehr, S. H., \& Thompson, W. B. (2009). The effects of head-mounted display mechanical properties and field-of-view on distance judgments in virtual environments. ACM Transactions on Applied Perception, 6, 8:1-8:14.

Willemsen, P., Gooch, A. A., Thompson, W. B., \& Creem-Regehr, S. H. (2008). Effects of stereo viewing conditions on distance perception in virtual environments. Presence: Teleoperators and Virtual Environments, 17, 91-101.

Witt, J. K., Stefanucci, J. K., Riener, C. R., \& Proffitt, D. R. (2007). Seeing beyond the target: Environmental context affects distance perception. Perception, 36, 1752-1768.

Wu, B., He, Z. J., \& Ooi, T. L. (2007). Inaccurate representation of the ground surface beyond a texture boundary. Perception, 36, 703-721.

Wu, J., Zhou, L., Shi, P., He, Z. J., \& Ooi, T. L. (2015). The visible ground surface as a reference frame for scaling binocular depth of a target in midair. Journal of Experimental Psychology: Human Perception and Performance, 41(1), 111-126. doi:10.1037/a0038287

Young, M.K, Gaylor, G.B, Andrus, S.M., \& Bodenheimer, B. (2014). A comparison of two cost-differentiated virtual reality systems for perception and action tasks. Proceedings of the ACM Symposium on Applied Perception, 83-90.

Ziemer, C. J., Plumert, J. M., Cremer, J. F., \& Kearney, J. K. (2009). Estimating distance in real and virtual environments: Does order make a difference? Attention, Perception, \& Psychophysics, 71, 1095-1106. doi:10.3758/APP.71.5.1096 